\title{
Impact of an Electronic Medical Record on Diabetes Quality of Care
}

Patrick J. O'Connor, MD, MPH

A. Lauren Crain, PbD

William A. Rush, PbD

JoAnn M. Sperl-Hillen, MD

Jay J. Gutenkauf, MD

Jane E. Duncan, MPH

HealthPartners Medical Group and HealthPartners Research Foundation, Minneapolis Minn
Conflict of interest: none reported

\section{CORRESPONDING AUTHOR}

Patrick O'Connor, MD, MPH

HealthPartners Research Foundation PO Box 1524

Minneapolis MN 55440-1524

patrick.j.oconnor@healthpartners.com

\begin{abstract}
PURPOSE This study was designed to evaluate the impact of electronic medical record (EMR) implementation on quality of diabetes care.

METHODS We conducted a 5-year longitudinal study of 122 adults with diabetes mellitus at an intervention (EMR) clinic and a comparison (non-EMR) clinic. Clinics had similarly trained primary care physicians, similar patient populations, and used a common diabetes care guideline that emphasized the importance of glucose control. The EMR provided basic decision support, including prompts and reminders for diabetes care. Preintervention and postintervention frequency of testing for glycated hemoglobin $\left(\mathrm{HbA}_{1 \mathrm{c}}\right)$ and low-density lipoprotein $(\mathrm{LDL})$ levels were compared with and without adjustment for patient age, sex, comorbidity, and baseline $\mathrm{HbA}_{1 \mathrm{c}}$ level.
\end{abstract}

RESULTS Frequency of $\mathrm{HbA}_{1 \mathrm{c}}$ tests increased at the EMR clinic compared with the frequency at the non-EMR clinic $(P<.001)$. $\mathrm{HbA}_{1 \mathrm{c}}$ levels improved in both clinics $(P<.05)$ with no significant differences between clinics 2 years $(P=.10)$ or 4 years $(P=.27)$ after EMR implementation. Similar results were observed for LDL levels.

CONCLUSIONS In this controlled study, EMR use led to an increased number of $\mathrm{HbA}_{1 \mathrm{c}}$ and LDL tests but not to better metabolic control. If EMRs are to fulfill their promise as care improvement tools, improved implementation strategies and more sophisticated clinical decision support may be needed.

Ann Fam Med 2005;3:300-306. DOI: 10.1370/afm.327.

\section{INTRODUCTION}

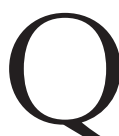
uality of outpatient diabetes care lags behind evidence-based care recommendations, ${ }^{1,2}$ and various strategies have been suggested to improve care. ${ }^{3-7}$ Electronic medical records (EMRs) have been proposed as an effective information management tool with the potential to improve diabetes care, ${ }^{8-10}$ and an Institute of Medicine report has identified key features of EMRs that may lead to better care. ${ }^{10}$

Currently available outpatient EMRs can identify patients with diabetes, assess whether the patient is due for recommended tests or screening procedures, and determine which patients have not achieved evidence-based clinical goals for glycemic, lipid, or blood pressure control. This information is typically presented to the clinician as reminders (patient due for a glycated hemoglobin $\left[\mathrm{HbA}_{1 \mathrm{c}}\right]$ test) or prompts (patient's $\mathrm{HbA}_{1 \mathrm{c}}$ level is above recommended level) delivered electronically at the point of care. Current diabetes care is characterized by high rates of clinical inertia, defined as failure to intensify treatment in patients who have not achieved evidence-based clinical goals. ${ }^{11,12}$ Rates of clinical inertia at diabetes visits exceed $50 \%$, and EMR technology seems well-suited to reducing this problem, thus improving care.

Currently only about $20 \%$ of primary care physicians report use of EMRs. Because of the well-established administrative and financial management advantages of EMRs and the pressure from payers, purchasers, and regulators of health care to use EMRs, investments in such technology are 
rapidly increasing. This rapid growth in EMR use is driven in part by a widespread belief that EMR use will improve clinical care.

Many uncontrolled studies have reported improvements in diabetes care temporally linked to EMR use. Because there is evidence of a widespread improvement trend in diabetes care in recent years, ${ }^{13-16}$ uncontrolled studies may overestimate the benefits of EMRs.${ }^{17}$ In controlled studies, current EMR systems have had limited positive impact on outpatient diabetes care. ${ }^{18-20}$ No study yet has found that EMR use has a significantly positive impact on glycemic control, although improvements in some diabetes processes of care have been documented. This study differs from previous reports by focusing on community primary care practices and evaluating the impact of a commercially available EMR used to provide all office care, not only diabetes care.

\section{METHODS}

This study was designed to assess whether implementation of an EMR in a primary care clinic significantly improves process of care (appropriate frequency of testing for $\mathrm{HbA}_{1 \mathrm{c}}$ and low-density lipoprotein [LDL]) or intermediate outcomes of care (change in $\mathrm{HbA}_{1 \mathrm{c}}$ and LDL levels) for adults with diabetes mellitus.

\section{Study Setting}

The study was conducted at HealthPartners Medical Group (HPMG), a multispecialty medical group in Minnesota that provided care to 175,000 adults in 18 clinics in 1996. The study was designed to take advantage of EMR implementation in 1 clinic of a multiclinic medical group by comparing results with those achieved in a clinic that was not using the EMR. On May 7, 1997, an EMR developed by Epic Systems was introduced at the intervention clinic, with extensive formal and ongoing one-on-one support provided to physicians. This EMR system included visit notes typed by physicians, automated ordering of pharmaceuticals, current displays of all laboratory and test results on request, a problem list, and other features. Physicians typically consulted the EMR on a computer monitor while in the examination room with each patient. All clinical data were loaded from several previous years, and after EMR implementation, paper charts were no longer available at the time of patient visits. An EMR enhancement in March 1998 included prompts to physicians if a patient with diabetes had no $\mathrm{HbA}_{1 \mathrm{c}}$ test within 6 months or no urine microalbuminuria test within 1 year. In mid-1999, further enhancements included prompts to physicians when diabetic patients had blood pressures of $\geq 130 / 85$ $\mathrm{mm} \mathrm{Hg}$, LDL levels of $\geq 130 \mathrm{mg} / \mathrm{dL}, \mathrm{HbA}_{1 \mathrm{c}}$ levels $\geq 8 \%$, or no aspirin use if aged 40 years or older. The prompts and reminders were visible on the screen, but a response to them was not obligatory. At no time during this study was the EMR widely used to provide information or printouts directly to patients.

The EMR clinic was relatively small, with a stable staff of 4 to 5 physicians, and was a system leader in quality of care. The comparison clinic was selected because it was similar to the EMR clinic in size, physician stability, and suburban location, and the diabetic patients had similar baseline $\mathrm{HbA}_{1 \mathrm{c}}$ test values. No residency training was done at either study clinic.

The EMR evaluated in this report was developed by Epic Systems (Madison, Wis) and updated regularly as new systems and technology were developed. Support was provided through Information Services at HealthPartners, with expert consultation from Epic as needed. The cost of the EMR at this clinic is not available for public disclosure, but more resources were invested in EMR implementation and maintenance than were invested for other care improvement interventions at the comparison clinic or at other clinics in the medical group during the study period. The EMR clinic participated in other diabetes-related care improvement activities within the medical group during the study period, as previously described. ${ }^{13}$ All clinics in the medical group had access to physician-specific diabetes registries that were distributed quarterly in printed form, in-clinic diabetes teaching nurses for patient education, and a common diabetes clinical guideline developed regionally by the Institute for Clinical Systems Improvement (http://www.icsi.org).

The EMR used a Windows interface and a Virtual Basic (Microsoft Corp, Redmond, Wash) operating system linked to laboratory test results and pharmacy databases. Each examination room had a computer screen and keyboard, and physicians typically constructed office notes and orders while in the examination room with the patient. Although we did not formally evaluate acceptability of the EMR to physicians or patients in this study, it is widely believed at the EMR clinic and within HPMG that both physicians and patients are quite satisfied with the system.

\section{Study Patients}

To evaluate the impact of the EMR on process and intermediate outcomes of diabetes care, we focused on all adults with an established diagnosis of diabetes at study baseline in both study clinics. Those older than 18 years were classified as having diabetes mellitus if in calendar year 1994 they had either (1) 1 or more inpatient or 2 or more outpatient ICD-9 codes for diabetes (ICD-9 codes 250.xx), or (2) a filled prescription for a diabetes-specific drug (insulins, sulfonylureas, metformin, thiazolidinediones, alpha-glucosidase inhibitors, meglitinides). This 
diabetes identification method was previously evaluated with estimated sensitivity of 0.91 , specificity of 0.99 , and positive predictive value of $0.94 .^{21}$

The clinic that each diabetes patient attended was identified in 1996, 1998, and 2000 based on number of visits and administrative data. Patients were included in the analysis only if they attended their original study clinic in all 3 of the study years and were still alive and enrolled in HPMG on December 31, 2000. We have previously shown that disenrollment rates for diabetes patients averaged 3.9\% a year from 1993 to 1996, and that the $\mathrm{HbA}_{1 \mathrm{c}}$ level was not a significant predictor of either death or disenrollment in adults with diabetes. ${ }^{22}$ There were 122 study patients who met these inclusion criteria and whose diabetes care data are analyzed in this report; of these patients, 57 received care at the EMR clinic and 65 received care at the comparison clinic.

\section{Dependent Variables}

Dependent variables included measures of diabetes process of care and measures of intermediate outcomes of diabetes care. Process of care measures included the number of $\mathrm{HbA}_{1 \mathrm{c}}$ tests and LDL cholesterol tests done for patients with diagnosed diabetes in each study clinic in each of the calendar years 1996, 1998, and 2000. Additional process measures assessed whether patients met minimum thresholds for $\mathrm{HbA}_{1 \mathrm{c}}$ and LDL testing. Specifically, 3 threshold measures assessed whether the patient had at least $2 \mathrm{HbA}_{1 \mathrm{c}}$ tests in a calendar year; at least 1 LDL test in a calendar year; or at least $2 \mathrm{HbA}_{1 \mathrm{c}}$ tests and $1 \mathrm{LDL}$ test in a calendar year.

Intermediate diabetes outcome measures included glycemic control and lipid control, as measured by $\mathrm{HbA}_{1 \mathrm{c}}$ and LDL test values in calendar years 1996, 1998, and 2000. All $\mathrm{HbA}_{1 \mathrm{c}}$ tests during the study period at these clinics were performed at a single accredited clinical chemistry laboratory using a standard liquid chromatography assay ${ }^{23}$ with a coefficient of variation of $0.58 \%$ at an $\mathrm{HbA}_{1 \mathrm{c}}$ value of $8.8 \%$ and a normal range of $4.5 \%$ to $6.1 \%$. In October 1998 a minor modification of the assay method was made, which did not change median $\mathrm{HbA}_{1 \mathrm{c}}$ values, but which led to statistically significant lower values for $\mathrm{HbA}_{1 \mathrm{c}}$ concentrations of more than $10 \%$. This change in assay applied equally to both clinics in the study in both timing and degree.

LDL cholesterol (LDL) was calculated from measures of total cholesterol, high-density lipoprotein cholesterol, and fasting ( 12 hours or more) triglycerides using a standard equation. ${ }^{24}$ All lipid assays were done in the same accredited clinical chemistry laboratory using standard assay techniques that did not change during the study period.

All test results from both clinics were entered directly into an electronic database at the central laboratory. In the EMR clinic, results were then downloaded into Epic. When collecting data for analysis, we drew all data from the electronic database at the central laboratory, assuring equivalent and complete capture of relevant laboratory test data for the EMR and comparison clinics. Neither clinic used desktop analyzers for any tests during the study period.

\section{Independent Variables}

There were 2 independent variables of interest. The first was an indicator of EMR use. The second was an indicator of the year $(1996,1998$, or 2000) in which the outcome measures were taken. The interaction between these 2 independent variables constituted the effect of most interest for the study. A significant interaction between time and EMR status would indicate that the relationship between time and testing (either test frequency or test values) was different as a function of whether the patient was in an EMR or comparison clinic. Examining predicted cell means in the context of a significant interaction could provide evidence of whether the rate of testing or values of tests performed improved more in the EMR clinic than in the comparison clinic.

\section{Covariates}

Covariates included patient age, sex, and Charlson comorbidity score. Age and sex were obtained from administrative records at HPMG. Charlson comorbidity score was based on the method of Charlson et $\mathrm{al}^{25}$ as modified by Deyo et $\mathrm{al}_{1}{ }^{26}$ and Rush et al. ${ }^{27}$ The modifications of Rush et al included (1) assigning points only when a diagnostic code appears 2 or more times during a 12-month period, and (2) excluding all points related to diabetes, because every patient in the analysis was identified as having diabetes as a condition of being in the study. This modified Charlson score has been validated and found to predict both mortality and costs of care. ${ }^{27}$ Because of the nonnormal distribution of the Charlson score, patients were grouped and analyzed according to whether their Charlson score was less than 2, 2, or more than 2.

\section{Plan of Analysis}

The analysis was designed to test 3 hypotheses: (1) EMR use predicts the number of $\mathrm{HbA}_{1 \mathrm{c}}$ and LDL tests performed, (2) EMR use predicts the proportion of patients with recommended number of $\mathrm{HbA}_{1 \mathrm{c}}$ and LDL tests in a given year, ${ }^{28,29}$ and (3) EMR use predicts change in values of $\mathrm{HbA}_{1 \mathrm{c}}$ and LDL tests with time.

Generalized linear modeling techniques (SAS version 8.2, SAS Institute, Cary, NC) were used to predict whether dependent variables changed with time in the EMR and comparison settings. Normally distrib- 
uted continuous outcome variables (test values) were predicted using PROC MIXED, specifying a normal distribution and identity link function. PROC GENMOD was used for binary outcomes (testing thresholds) specifying a logit link function and a binomial distribution. Number of tests was predicted using both the normal distribution with an identity link function and the Poisson distribution with a log link function in PROC GENMOD with identical results. In all models, the unit of analysis was the patient, and the covariance structure among the repeated measures was unspecified We evaluated relevant interaction terms and included those that were significant.

\section{Human Subjects Protection}

The study was reviewed in advance, approved, and monitored by the HealthPartners Institutional Review Board.

\section{RESULTS}

Table 1 shows that study patients at the 2 clinics had similar age, sex, and Charlson score distributions.

Table 2 shows that the number of $\mathrm{HbA}_{1 \mathrm{c}}$ tests performed per patient per year in the EMR clinic increased significantly relative to the number of $\mathrm{HbA}_{1 \mathrm{c}}$ tests at the comparison clinic both 2 years $(P<.04)$ and 4 years $(P<.001)$ after the EMR was introduced. There were no significant effects of any other covariates on $\mathrm{HbA}_{1 \mathrm{c}}$ test rates. The number of LDL tests performed per patient per year significantly increased from 1996 to 2000 in both clinics $(P<.001)$, with no significant difference in the rate of increase between the EMR and comparison clinics. There were no significant effects of any other covariates on LDL test rates.

Next, we tested whether the proportion of patients receiving the recommended number of $\mathrm{HbA}_{1 \mathrm{c}}$ tests increased with time in the EMR clinic relative to the comparison clinic. The increase in predicted testing rates in the EMR clinic in 1998 was only marginally larger than the increase in the comparison clinic, from $55.4 \%$ in 1996 to $63.1 \%$ in $1998, P=.09$ (Table 3). Through 2000 , however, the predicted test rates increased further in the EMR clinic but not in the comparison clinic, $P=$ .02. There were no significant effects involving any of the covariates.

An analogous model predicted LDL tests and showed a different pattern of results. The predicted proportion of patients meeting the LDL testing standard at both clinics had increased by year $2000(P$ $<.001)_{i}$ however, there were no significant differences in LDL test rate between clinics either 2 years $(P=.12)$ or 4 years $(P=.12)$ after EMR implementation.

A third model tested whether the proportion of patients who met both the $\mathrm{HbA}_{1 \mathrm{c}}$ and LDL testing thresholds increased with time and by EMR clinic.

The predicted proportion of patients meeting both the $\mathrm{HbA}_{1 \mathrm{c}}$ and LDL thresholds increased significantly from

\begin{tabular}{|c|c|c|c|}
\hline $\begin{array}{l}\text { Patient } \\
\text { Characteristic }\end{array}$ & $\begin{array}{l}\text { EMR Clinic } \\
\mathrm{n}=57\end{array}$ & $\begin{array}{c}\text { Comparison } \\
\text { Clinic } \\
n=65\end{array}$ & $P$ Value \\
\hline $\begin{array}{l}\text { Age, mean (SE) } \\
\text { years }\end{array}$ & $\begin{array}{l}60.6 \\
(1.62)\end{array}$ & $\begin{array}{l}59.4 \\
(1.72)\end{array}$ & .34 \\
\hline Male, \% & 54.4 & 58.5 & .65 \\
\hline Charlson* $<2, \%$ & 73.7 & 75.4 & .97 \\
\hline Charlson $=2, \%$ & 15.8 & 15.4 & \\
\hline Charlson $>2, \%$ & 10.5 & 9.2 & \\
\hline
\end{tabular}

Table 2. Adjusted Number of $\mathrm{HbA}_{1 \mathrm{c}}$ and LDL Tests Performed on Patients in the EMR and Comparison Clinics in a 12-Month Period

\begin{tabular}{lccc}
\hline Test & $\begin{array}{c}\text { EMR } \\
\mathbf{n}=\mathbf{5 7}\end{array}$ & $\begin{array}{c}\text { Comparison } \\
\mathbf{n}=\mathbf{6 5}\end{array}$ & $\begin{array}{c}\text { Time by EMR } \\
\mathbf{P} \text { Value }\end{array}$ \\
\hline $\mathrm{HbA}_{1 \mathrm{c}}$ tests, No. & & & \\
1996 & 1.67 & 1.75 & .04 \\
1998 & 2.20 & 1.83 & .001 \\
2000 & 2.46 & 1.63 & \\
LDL tests, No. & & .49 & .33 \\
1996 & .54 & .59 & .19 \\
1998 & .87 & .92 & \\
2000 & 1.45 & & \\
\hline $\mathrm{HbA}_{1 \mathrm{C}}=$ glycated hemoglobin; LDL $=$ low-density lipoprotein cholesterol; \\
$\mathrm{EMR}^{2}$ electronic medical record.
\end{tabular}

Table 3. Percentage of Patients Having at Least $2 \mathrm{HbA}_{1 \mathrm{c}}$ Tests, 1 LDL Test, or $2 \mathrm{HbA}_{1 \mathrm{c}}$ and $1 \mathrm{LDL}$ Tests per Year in the EMR and Comparison Clinics

\begin{tabular}{|c|c|c|c|}
\hline Test & $\begin{array}{c}\text { EMR } \\
n=57\end{array}$ & $\begin{array}{c}\text { Comparison } \\
n=65\end{array}$ & $\begin{array}{c}\text { Time by EMR } \\
P \text { Value }\end{array}$ \\
\hline \multicolumn{4}{|c|}{$\geq 2 \mathrm{HbA}_{1 \mathrm{c}}$ tests } \\
\hline 1996 & 47.4 & 55.4 & \\
\hline 1998 & 73.7 & 63.1 & .09 \\
\hline 2000 & 78.9 & 53.9 & .002 \\
\hline \multicolumn{4}{|c|}{$\geq 1$ LDL test } \\
\hline 1996 & 42.1 & 46.2 & \\
\hline 1998 & 68.4 & 55.4 & .12 \\
\hline 2000 & 84.2 & 72.3 & .12 \\
\hline \multicolumn{4}{|c|}{$\begin{aligned} \geq & 2 \mathrm{HbA}_{1 \mathrm{c}} \text { and } \\
& 1 \mathrm{LDL} \text { test }\end{aligned}$} \\
\hline 1996 & 29.8 & 30.8 & \\
\hline 1998 & 57.9 & 46.2 & .27 \\
\hline 2000 & 70.2 & 46.2 & .03 \\
\hline
\end{tabular}


1996 to $1998(P<.05)$, and showed an even greater increase from 1996 to $2000(P<.01)$. The increase between 1996 and 1998 was similar in the EMR and comparison clinics $(P=.27)$, but the increase between 1996 and 2000 was larger in the EMR than in the comparison clinic $(P=.03)$.

Table 4 and Figure 1 show that patients in the EMR and comparison clinics had similar $\mathrm{HbA}_{1 \mathrm{c}}$ values in 1996. These values were stable from 1996 to 1998 but improved significantly by year $2000(P<.05)$. Patients at the EMR clinic, however, did not have more improvement in $\mathrm{HbA}_{1 \mathrm{c}}$ values than their non-EMR counterparts either 2 years $(P=.10)$ or 4 years $(P=$ .27) after EMR implementation. The only significant effect involving covariates showed that older patients had lower $\mathrm{HbA}_{1 \mathrm{c}}$ values $(P<.0002)$.

Table 4. Predicted Least Squares Mean $\mathrm{HbA}_{1 c}$ Test Values in Clinics With Time, Adjusted for Patient Age, Sex, and Charlson Comorbidity Score

\begin{tabular}{lccc}
\hline Year & $\begin{array}{c}\text { EMR } \\
\mathbf{n}=\mathbf{4 6}\end{array}$ & $\begin{array}{c}\text { Comparison } \\
\mathbf{n}=\mathbf{5 0}\end{array}$ & $\begin{array}{c}\text { Time by EMR } \\
\mathbf{P} \text { Value }\end{array}$ \\
\hline $\begin{array}{l}1996 \mathrm{HbA}_{1 c} \\
\text { value }\end{array}$ & 7.80 & 7.35 & \\
$\begin{array}{l}1998 \mathrm{HbA}_{1 c} \\
\text { value }\end{array}$ & 7.90 & 7.26 & .10 \\
$\begin{array}{l}2000 \mathrm{HbA} \\
\text { value }\end{array}$ & 7.71 & 7.11 & .27 \\
\hline $\mathrm{HbA}_{1 \mathrm{c}}=$ glycated hemoglobin; EMR = electronic medical record. \\
\hline
\end{tabular}

Figure 1. Observed $\mathrm{HBA}_{1 \mathrm{c}}$ improvement with time in EMR and non-EMR clinics, Minnesota, 1996-2000.

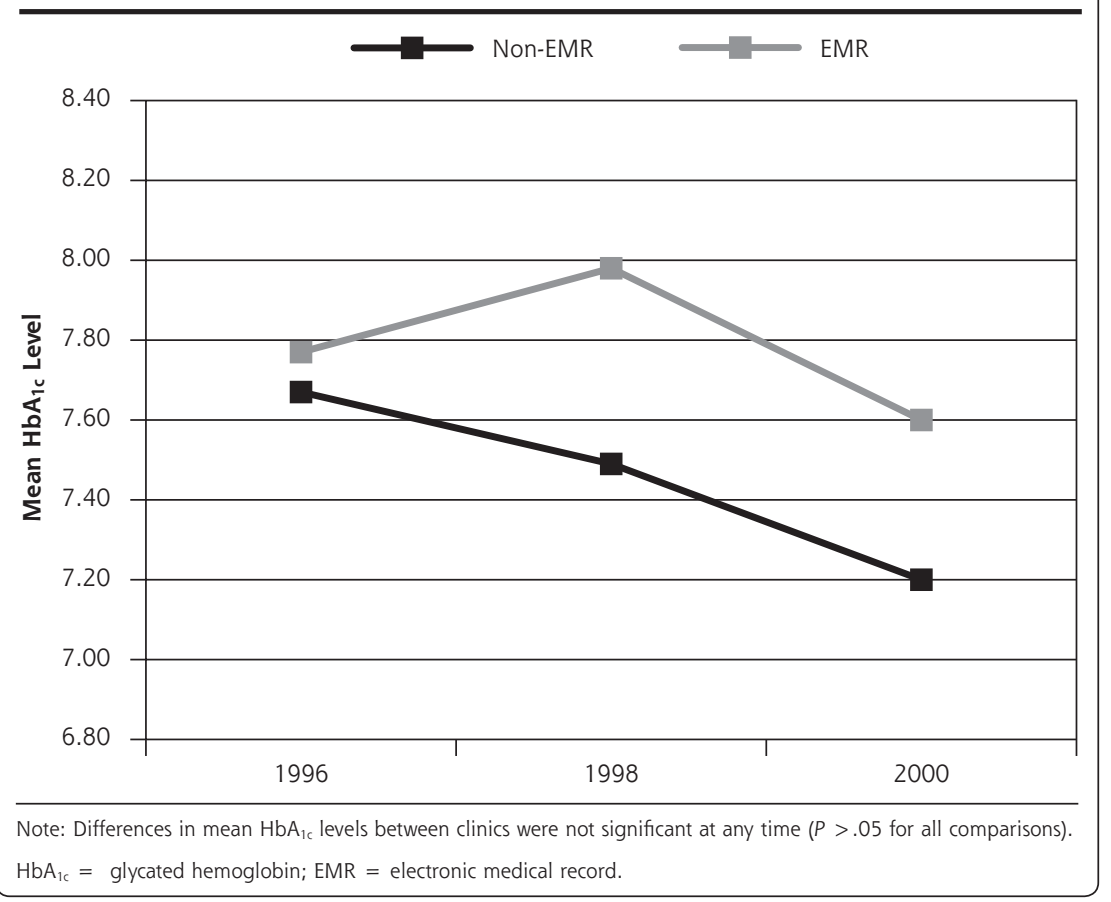

Although we had planned to also analyze the relationship of EMR status on change in LDL levels with time, there were too few patients with LDL measurements during the 3 periods to provide stable statistical estimates. The results of these analyses are therefore not shown. There was no evidence, however, that EMR use led to lower LDL levels.

\section{DISCUSSION}

In this study EMR use was associated with improved process of care for adults with diabetes. Patients who attended the EMR clinic had more $\mathrm{HbA}_{1 \mathrm{c}}$ tests than patients in the comparison clinic, and more patients in the EMR clinic met recommended thresholds for $\mathrm{HbA}_{1 \mathrm{c}}$ and LDL test frequency than did patients in the comparison clinic. There was no evidence, however, that this change in process of care led to better glycemic control in the EMR clinic patients during the 4-year follow-up period.

\section{Implications of Findings for EMR Design}

The data suggest that despite the substantial cost and increasing technical sophistication of EMRs, EMR use failed to achieve desirable levels of clinical improvement. Although it is commendable to perform regular $\mathrm{HbA}_{1 \mathrm{c}}$ testing, it is the $\mathrm{HbA}_{1 \mathrm{c}}$ level, not the number of $\mathrm{HbA}_{1 \mathrm{c}}$ tests done, that predicts future risk of complications and increased health care costs. ${ }^{30-32}$ Moreover, recommendations for $\mathrm{HbA}_{1 \mathrm{c}}$ test frequency are not based on clinical trial data, but on expert opinion, whereas the $\mathrm{HbA}_{1 \mathrm{c}}$ level has been shown in clinical trials to be a strong predictor of outcomes and a moderate predictor of costs. The tenuous link between process and outcome of diabetes care is well described in the literature; frequency of tests and procedures is not strongly linked to $\mathrm{HbA}_{1 \mathrm{c}}$ levels or clinical events. ${ }^{33,34}$

$\mathrm{HbA}_{1 \mathrm{c}}$ levels at both study clinics had been improving steadily for 4 years before implementation of the EMR. After EMR implementation, $\mathrm{HbA}_{1 \mathrm{c}}$ levels in the EMR clinic worsened for a period of about 2 years. This finding suggests an urgent need to develop more effective and less disruptive methods of introducing EMRs into clinics. 
Figure 1 shows that the slope of improvement for $\mathrm{HbA}_{1 \mathrm{c}}$ levels in the EMR clinic was similar that for the non-EMR clinic after the EMR implementation period. This observation underscores that there are many ways to improve $\mathrm{HbA}_{1 \mathrm{c}}$ levels in the absence of EMRs - in fact, most recent reports of successful improvement in $\mathrm{HbA}_{1 \mathrm{c}}$ levels in the published literature were accomplished without the aid of EMRs. ${ }^{13-16}$

That the EMR clinic did not outperform the nonEMR clinic indicates the need to further enhance the capabilities of EMRs. Based on our work and that of others, there are 2 particular domains of care where EMR performance needs major improvement. ${ }^{35,36}$ The first domain is more sophisticated clinical decision support. For example, EMRs can integrate data on patient age, current $\mathrm{HbA}_{1 \mathrm{c}}$ levels, renal function, liver function, comorbid conditions, and current medications to recommend specific changes in treatment that may be beneficial. Algorithm-driven decision support is now becoming more widely available in commercial EMRs, but it is utilized only in a minority of practices. ${ }^{10,37}$

The second unrealized frontier is effective use of the EMR as a patient education and patient activation tool. ${ }^{38,39}$ Although computerized information support to patients has shown promise in recent studies ${ }^{40}$ additional strategies, such as patient access to the medical record, prompts and reminders to patients, and generation of customized information and educational materials through EMR databases, should be more completely developed and evaluated.

\section{Limitations of the Study}

There are a number of factors that limit the interpretation of the data presented here. First, we tested only 1 EMR version. Future versions of the EMR that include more advanced decision support and patient activation features may lead to greater improvements in care. Second, it is possible that unmeasured factors differentially distributed across groups could have affected our results. Patient demographic differences were small, however, and the analysis controlled for relevant patient characteristics including age, sex, and comorbidity. It is unlikely that results are due to differences in physicians, because similar primary care physicians from the same medical group staffed both clinics, and in other analyses the proportion of variance in diabetes care attributable to physicians has been small. ${ }^{41-43} \mathrm{~A}$ ceiling effect cannot account for the results, because the mean $\mathrm{HbA}_{1 \mathrm{c}}$ level in the final year of the study was $7.4 \%$, substantially higher than the recommended goal of $\mathrm{HbA}_{1 \mathrm{c}}$ level of less than $7 \%$.

It is worth noting that our finding of the lack of impact of EMRs on $\mathrm{HbA}_{1 \mathrm{c}}$ levels is mirrored by other recent reports showing lack of significant impact of
EMRs on lipid control, ${ }^{19}$ blood pressure control ${ }^{44}$ and treatment of patients with heart disease. ${ }^{45}$ Our data suggest the need to incorporate improved clinical decision support and more potent patient activation applications if EMRs are to fulfill their promise as an effective tool to improve diabetes care. Medical groups considering EMR systems should carefully evaluate EMR capacity to provide sophisticated clinical decision support, patient education, and activation and to support other functions that have been linked to better chronic disease care, such as diabetes registries, active outreach, and visit planning. In the absence of more advanced EMR capabilities, less expensive and less disruptive care-improvement strategies may improve chronic disease care as effectively as EMRs.

To read or post commentaries in response to this article, see it online at http://www.annfammed.org/cgi/content/full/3/4/300.

Key words: Medical records systems, computerized; diabetes mellitus; quality of health care; primary health care; diabetic control; disease management; medical decision making, computer-assisted; informatics; endocrinological system/metabolism; practice-based research; electronic medical records

Submitted October 8, 2004; submitted, revised, January 17, 2005; accepted February 19, 2005.

Funding support: This study was supported by a grant from HealthPartners Research Foundation.

\section{References}

1. Mokdad AH, Bowman BA, Ford ES, Vinicor F, Marks JS, Koplan JP. The continuing epidemics of obesity and diabetes in the United States. JAMA. 2001;286:1195-1200.

2. Marrero DG. Current effectiveness of diabetes health care in the United States. Diabetes Rev. 1994;2:292-309.

3. Committee on Quality of Health Care in America. Crossing the Quality Chasm: A New Health System for the 21st Century. Washington, DC, National Academy Press; 2001.

4. Institute of Medicine (IOM). To err is human: building a safer health system. Washington, DC: National Academy Press; 2000

5. O'Connor PJ, Solberg LI, Baird M. The future of primary care. The enhanced primary care model. J Fam Pract. 1998;47:62-67.

6. Wagner EH, Austin BT, Korff MV. Improving outcomes in chronic illness. Managed Care Q. 1996;4:12-25.

7. Ornstein SM, Jenkins RG, MacFarlane L, Glaser A, Snyder K, Gundrum T. Electronic medical records as tools for quality improvement in ambulatory practice: theory and a case study. Top Health Inf Manage. 1998; 19:35-43.

8. Selby JV, Karter AJ, Ackerson LM, Ferrara A, Liu J. Developing a prediction rule from automated clinical databases to identify highrisk patients in a large population with diabetes. Diabetes Care. 24: 2001;1547-1555.

9. Barahona P, Azevedo F, Veloso M, Estevao N, Gallego R. Computerising a guideline for the management of diabetes. Int J Med Inf. 2001; 64:275-284.

10. Institute of Medicine. Key Capabilities of an Electronic Health Record System: Letter Report. Washington, DC: Institute of Medicine of the National Academies, http://www.nap.edu, 2003:31. 
11. Phillips LS, Branch WT, Cook CB, et al. Clinical inertia. Ann Intern Med. 2001;135:825-834.

12. O'Connor PJ, Sperl-Hillen JM, et al. (2005). Clinical inertia and outpatient medical errors. In: Henriksen K, Battles J, Lewin D, Marks E. Advances in Patient Safety: From Research to Implementation. Vol 2. Rockville, Md: Agency for Healthcare Research and Quality (AHRQ); 2005:293-308

13. Sperl-Hillen J, O'Connor PJ, Carlson RR, et al. Improving diabetes care in a large health care system: an enhanced primary care approach. Jt Comm J Qual Improv. 2000;26:615-622.

14. Nyman MA, Murphy ME, Schryver PG, Naessens JM, Smith SA. Improving performance in diabetes care: a multicomponent intervention. Eff Clin Pract. 2000;3:205-212.

15. Sidorov J, Gabbay R, Harris R, Shull RD, Girolami S, Tomcavage J, Starkey R, Hughes R. Disease management for diabetes mellitus: impact on Hemoglobin A1c. Am J Manag Care. 2000;6:1217-1226.

16. Sutherland JE, Hoehns JD, O'Donnell B, Wiblin RT. Diabetes management quality improvement in a family practice residency program. J Am Board Fam Pract. 2001;14:243-251.

17. Hunt D, Haynes A, Hanna S, Smith K. Effects of computer-based decision support systems in physician performance and patient outcomes: a systematic review. JAMA. 1998;280:1339-1346.

18. Meigs JB, Cagliero E, Dubey A, et al. A controlled trial of web-based diabetes disease management: the MGH diabetes primary care improvement project. Diabetes Care. 2003;26:750-757.

19. Montori VM, Dinneen SF, Gorman CA, et al. The impact of planned care and a diabetes electronic management system on communitybased diabetes care: the Mayo Health System Diabetes Translation Project. Diabetes Care. 2002;25:1952-1957.

20. Kerr EA, Gerzoff RB, Krein SL, Selby JV, Piette JD, et al. Diabetes care quality in the Veterans Affairs health care system and commercial managed care: the TRIAD study. Ann Intern Med. 2004;141:272-281.

21. O'Connor P, Rush W, Pronk N, Cherney L. Identifying diabetes mellitus or heart disease among health maintenance organization members: sensitivity, specificity, predictive value and cost of survey and database methods. Am J Manag Care. 1998; 4:335-342.

22. Gilmer TG, O'Connor PJ, Rush WA. Does baseline HbA1c predict subsequent HMO disenrollment? In American Diabetes Association's 58th Annual Meeting and Scientific Sessions. Chicago, III: American Diabetes Association; 1998:A190.

23. Huisman TH, Henson JB, Wilson JB. A new high-performance liquid chromatographic procedure to quantitate hemoglobin A1c and other minor hemoglobins in blood of normal, diabetic, and alcoholic individuals. J Lab Clin Med. 1983;102:163-173.

24. Friedewald WT, Levy RI, Fredrickson DS. Estimation of the concentration of low-density lipoprotein cholesterol in plasma, without use of the preparative ultracentrifuge. Clin Chem. 1972;18:499-502.

25. Charlson ME, Pompei P, Ales KL, MacKenzie CR. A new method of classifying prognostic comorbidity in longitudinal studies: development and validation. J Chronic Dis. 1987;40:373-383.

26. Deyo RA, Cherkin DC, Ciol MA. Adapting a clinical comorbidity index for use with ICD-9-CM administrative databases. J Clin Epidemiol. 1992:45:613-619.

27. Rush WA, O'Connor PJ, Goodman MJ. Validation of a modified Charlson score for using health plan claims data. In Minnesota Health Services Research Conference. Minneapolis, Minn: University of Minnesota; 2000.
28. ICSI. Clinical care guideline: treatment of type 2 diabetes mellitus. Bloomington, Minn: Institute for Clinical Systems Integration; 1999.

29. ADA. Clinical practice recommendations 1999. Diabetes Care. 1999;22(Suppl 1).

30. Gilmer TP, O'Connor PJ, Manning WG, Rush WA. The cost to health plans of poor glycemic control. Diabetes Care. 1997;20:1847-1853.

31. Gilmer TP, O'Connor PJ, Rush WA, et al. Predictors of health care costs in adults with diabetes. Diabetes Care. 2005;28:59-64.

32. Intensive blood-glucose control with sulphonylureas or insulin compared with conventional treatment and risk of complications in patients with type 2 diabetes (UKPDS 33). UK Prospective Diabetes Study (UKPDS) Group. Lancet. 1998;352:837-853.

33. Greenfield S, Rogers W, Mangotich M, Carney MP, Tarlov AR. Outcomes of patients with hypertension and non-insulin-dependent diabetes mellitus treated by different systems and specialists. Results from the Medical Outcomes Study. JAMA. 1995;274:1436-1444.

34. O'Connor PJ, Fragneto R, Coulehan J, Crabtree BF. Metabolic control in non-insulin-dependent diabetes mellitus: factors associated with patient outcomes. Diabetes Care. 1987;10:697-701.

35. O'Connor PJ, Sperl-Hillen JM, Pronk NP, Murray T. Primary care clinic-based chronic disease care: features of successful programs. Dis Manage Health Outcomes. 2001;9:691-698.

36. Sperl-Hillen JM, Solberg LI, Hroscikoski MC, Crain AL, Engebretson KI, O'Connor PJ. Do all components of the chronic care model contribute equally to quality improvement? Jt Comm J Qual Saf. 2004;30:303-309.

37. Mazze R, Strock E, Simonson G, Bergenstal R, Etzwiler D. Staged Diabetes Management: Detection and Treatment. Minneapolis, Minn: International Diabetes Center; 2001.

38. Greenfield S, Kaplan SH, Ware JE Jr, Yano EM, Frank HJ. Patients participation in medical care: effects on blood sugar control and quality of life in diabetes. J Gen Intern Med. 1988;3:448-457.

39. Renders CM, Valk GD, Griffin SJ, Wagner EH, Eijk Van JT, Assendelft WJ. Interventions to improve the management of diabetes in primary care, outpatient, and community settings: a systematic review. Diabetes Care. 2001;24:1821-1833.

40. Balas EA, Krishna S, Kretschmer RA, Cheek TR, Lobach DF, Boren SA. Computerized knowledge management in diabetes care. Med Care. 2004;42:610-621.

41. Hofer TP, Hayward RA, Greenfield S, Wagner EH, Kaplan SH, Manning WG. The unreliability of individual physician "report cards" for assessing the costs and quality of care of a chronic disease. JAMA. 1999; 281:2098-2105.

42. Krein SL, Hofer TP, Kerr EA, Hayward RA. Whom should we profile? Examining diabetes care practice variation among primary care providers, provider groups, and health care facilities. Health Serv Res. 2002;37:1159-1180

43. O'Connor PJ, Rush WA, Gilmer TP, et al. Final Report: Organizational Characteristics and Chronic Disease. Minneapolis, Minn: HealthPartners Research Foundation and University of Minnesota Carlson School of Management; 2004.

44. Murray MD, Harris LE, Overhage JM, et al. Failure of computerized treatment suggestions to improve health outcomes of outpatients with uncomplicated hypertension: results of a randomized controlled trial. Pharmacotherapy. 2004;24:324-337.

45. Tierney WM, Overhage JM, Murray MD, et al. Effects of computerized guidelines for managing heart disease in primary care. J Gen Intern Med. 2003:18:967-976. 